\title{
Expression of toll-like receptors and type 1 interferon specific protein MxA in biliary atresia
}

\author{
Ying-Hsien Huang ${ }^{1}$, Ming-Huei Chou ${ }^{2}$, Yung-Ying Du², Chao-Cheng Huang ${ }^{3}$, \\ Chia-Ling $\mathrm{Wu}^{2}$, Chao-Long $\mathrm{Chen}^{2}$ and Jiin-Haur Chuang ${ }^{2}$
}

${ }^{1}$ Department of Pediatrics, Chang Gung Memorial Hospital-Kaohsiung Medical Center and the Graduate Institute of Clinical Medical Sciences, Chang Gung University College of Medicine, Kaohsiung, Taiwan, ROC; ${ }^{2}$ Department of Surgery, Chang Gung Memorial Hospital-Kaohsiung Medical Center and the Graduate Institute of Clinical Medical Sciences, Chang Gung University College of Medicine, Kaohsiung, Taiwan, ROC and ${ }^{3}$ Department of Pathology, Chang Gung Memorial Hospital-Kaohsiung Medical Center and the Graduate Institute of Clinical Medical Sciences, Chang Gung University College of Medicine, Kaohsiung, Taiwan, $R O C$

\begin{abstract}
Viral infection and type I interferon have been implicated in the pathogenesis of biliary atresia (BA), but the expression of toll-like receptors (TLRs) that recognize viruses, as well as of type 1 interferon specific signaling molecules are still unknown in BA. Fresh liver tissues were obtained from patients in early and late stage of BA and from patients with choledochal cyst (CC), as well as from normal controls receiving liver resection for benign lesion other than cholestasis or fibrosis. Archived liver tissues from patients with neonatal hepatitis (NH) were obtained for immunohistochemical studies. TLR2, 3, 4, 7 and 9 that recognized Gram-positive bacteria, double-stranded RNA virus, lipopolysaccharide, single-stranded RNA virus and DNA virus, respectively, were studied. Real-time quantitative reverse transcription polymerase chain reaction (QRT-PCR) was used to quantitate TLR, type I interferon specific molecule MxA, interleukin-6 (IL-6) and IL-8 mRNA expression and immunohistochemistry for TLR 7 and MxA protein staining. These results show that there were significantly higher TLR7 and lower TLR3 and TLR9 mRNA expression in early stage of BA than in CC. MxA mRNA expression was also significantly higher in early stage of BA and in CC than in late stage of BA. Immunoreactive TLR7 and MxA staining was higher in early stage of BA than in late stage of BA, NH and CC, which was associated with significantly higher IL-8 mRNA expression in BA than in CC. The results implicate involvement of TLRs, particularly TLR7, and type 1 specific interferon signaling in the pathogenesis of BA, especially in early stage, which is associated with upregulation of inflammatory cytokines IL-8.
\end{abstract}

Laboratory Investigation (2007) 87, 66-74. doi:10.1038/labinvest.3700490; published online 30 October 2006

Keywords: biliary atresia; immunohistochemistry; interleukin-6; interleukin-8; MxA; toll-like receptors

Biliary atresia (BA) is characterized by progressive destruction and obliteration of the extrahepatic bile ducts within months of birth. The exact etiology and pathogenesis of BA is still unknown. Despite improvement of survival with the use of Kasai's Procedure, more than half of the patients still end up with liver cirrhosis necessitating liver transplantation. $^{1,2}$

Correspondence: Dr J-H Chuang, MD, Department of Surgery, Chang Gung Memorial Hospital at Kaohsiung, 123 Ta-Pei Road, Niao-Sung Hsiang, Kaohsiung, Taiwan 833, ROC.

E-mail: jhchuang@adm.cgmh.org.tw

Received 12 July 2006; revised 11 September 2006; accepted 13 September 2006; published online 30 October 2006
Infectious pathogens, particular viruses, have long been suggested as the causative agents, but none are universally isolated or identified in every case of BA. $^{3-6}$ In animal models of extrahepatic bile duct injury, mice infected with reovirus type 3 or rotavirus causes a fibrosclerosing lesion of the murine extrahepatic bile duct, which mimics BA and supports the infectious etiology of BA in humans. ${ }^{7,8}$ In Shivakumar's study of neonatal mice, rotavirus has a unique tropism to bile duct cells, which triggers hepatobiliary inflammation by IFN- $\gamma$ producing CD4 + and CD8 + lymphocytes. ${ }^{9}$

The infectious etiologies are frequently associated with their characteristic activation of the innate immune system by triggering pattern recognition 
receptors on the immune cells. Toll-like receptors (TLRs) are the most recognized pattern recognition receptors and TLR signaling is the telltale sign of activation of the innate immunity. ${ }^{10}$ TLR2, 3, 4, 7 and 9 recognize Gram-positive bacteria, doublestranded RNA virus, lipopolysaccharide, singlestranded RNA virus and bacterial DNA containing the unmethylated CpG motif and DNA viruses, respectively. ${ }^{11}$ None of the receptors have been implicated in the pathogenesis of BA.

Interferons (IFNs) are recognized for their ability to impede viral replication. IFN signaling is becoming an emerging bridge between TLR-mediated innate immunity and microorganisms. ${ }^{12,13}$ In the mouse model of extrahepatic biliary obstruction, IFN- $\gamma$ are implicated in the disease process. ${ }^{9,14}$ It is reasonable to assume that IFN signaling is implicated in the pathogenesis of BA. The aim of present study was to characterize the expression of TLRs and MxA. The latter is an important signaling molecule specific for type I IFN. ${ }^{15,16}$ The expression of pro-inflammatory cytokines interleukin-6 (IL-6) and interleukin-8 (IL-8) was also studied to characterize their association with TLR expression in BA. ${ }^{17}$

\section{Materials and methods}

\section{Patients and Samples}

Fresh liver tissues were obtained from four male and six female patients at the early stage of BA when they received Kasai's Procedure (KP) and three male and six female patients at the late stage of BA when they received liver transplantation (LT). Ten liver samples, which served as disease controls, were from fours male and six female patients of choledochal cyst (CC) when they underwent surgical intervention.

Most patients in this study did not have evidence of hepatitis B virus infection. The rationale to use CC as disease control is that the etiology is more likely to be a congenital abnormal anatomical arrangement than be infectious origin, as anomalous pancreaticobiliay ductal juction is still prevalent in CC. ${ }^{18}$ In support of the congenital theory is the fact that CC have been reported at 15 weeks' gestational age. ${ }^{19}$ The pathogenesis of CC is also different from $\mathrm{BA}$ and the change of the liver histology is milder, especially in children. Five normal control (CO) liver samples were from two male and three female patients undergoing liver resection for benign lesion of various causes in which the livers were devoid of fibrosis and cholestasis. Detailed history of the patients was recorded, including age when the patient received operation, sex and serum aspartate aminotransferase, alanine aminotransferase and total bilirubin (Table 1). Our entire BA patients belonged to nonsyndromic type. The mean age of these patients in the early and the late stage of BA, $\mathrm{CC}$ and $\mathrm{CO}$ was $2.1 \pm 0.6,18.1 \pm 8.9,36.7 \pm 30.8$ and $30.5 \pm 28.5$ months, respectively. After surgical removal, all the liver samples were immediately divided into four pieces, put into cryogenic vials $\left(\mathrm{CORNING}^{\mathbb{R}}\right)$, immersed in liquid nitrogen and then stored at $-80^{\circ} \mathrm{C}$ until use. The study was executed after approval of the Ethics and Clinical Research Committee of the Chang Gung University, and informed consent had been obtained from the parents.

\section{RNA Isolation and Real-Time Quantitative RT-PCR}

To quantitate the tissue amount of TLR2, 3, 4, 7 and 9, MxA, IL-6 and IL-8 mRNA, we used real-time quantitative reverse transcription polymerase chain reaction (QRT-PCR) with ABI 7700 Sequence Detection System (TaqMan, Perkin-Elmer Applied Biosystems). The system is a sensitive and reliable method for RNA quantitation. ${ }^{20}$ The reagent mixture was prepared according to the protocol provided by the manufacturer (Protech technology, Taipei, Taiwan). Total RNA ( $2 \mu \mathrm{g}$ ) extracted from the liver was used to generate cDNA using an oligodeoxynucleotide primer (oligo dT15) following the protocol for transcription (Promega, Madison, WI). PCR was performed in $50 \mu \mathrm{l}$ SYBR Green PCR Master Mix (Applied Biosystems) containing $10 \mu \mathrm{M}$ forward primers and reverse primers, and approximately $30 \mathrm{ng}$ cDNA. The primers sequences were listed in Table 2.

Amplification and detection were performed with the following profile: one cycle of $95^{\circ} \mathrm{C}$ for

Table 1 Demographic and clinical data in 35 children for QRT-PCR study

\begin{tabular}{|c|c|c|c|c|}
\hline Clinical feature & $\begin{array}{c}\text { Early stage of } B A \\
\mathrm{n}=10\end{array}$ & $\begin{array}{l}\text { Late stage of } B A \\
\mathrm{n}=10\end{array}$ & $\begin{array}{l}\text { Choledochal cyst } \\
\mathrm{n}=10\end{array}$ & $\begin{array}{l}\text { Control } \\
\mathrm{n}=5\end{array}$ \\
\hline Age (month) & $2.1 \pm 0.6$ & $18.1 \pm 8.9$ & $36.7 \pm 30.8$ & $30.5 \pm 28.5$ \\
\hline Gender (male:female) & $4: 6$ & $3: 7$ & $4: 6$ & $2: 3$ \\
\hline AST (IU/l) & $151 \pm 118$ & $386 \pm 530$ & $112 \pm 152$ & WNL or NA \\
\hline ALT (IU/l) & $108 \pm 90$ & $114 \pm 51$ & $80 \pm 98$ & WNL or NA \\
\hline Total bilirubin ( $\mu$ mole/l) & $160 \pm 44$ & $212 \pm 116$ & $38 \pm 48^{*}$ & WNL or NA \\
\hline
\end{tabular}

Value expressed as mean \pm s.d. ${ }^{*} P<0.05$ compared to early stage of BA.

$\mathrm{WNL}=$ within normal limit; NA $=$ not available.

$n=$ number of patients. 
Table 2 Primer sequences of TLRs, MxA, IL-6, IL8 and $\beta$-actin

\begin{tabular}{|c|c|c|}
\hline Genes & Forward primers & Reverse primers \\
\hline TLR2 & 5'-GATGTCCGCCTCTCGGTGT-3' & 5'-GCAGGAACAGAGCACAGCAC-3' \\
\hline TLR3 & 5'-TGGTTGGGCCACCTAGAAGT-3' & 5'-CCATTCCTGGCCTGTGAGTT-3' \\
\hline TLR4 & 5'-ATGGCTTGTCCAGTCTCGAAGT-3' & 5'-CAGGAAGGTCAAGTTTCTCAGCTC-3' \\
\hline TLR7 & 5'-TGCTGTGTGGTTTGTCTGGTG-3' & 5'-CTCCTGGCCCCACACAAGT-3' \\
\hline TLR9 & $5^{\prime}$-CCACAACAACATCCACAgCC-3' & $5^{\prime}$-GTGCATTGCCGCTGAAGTC-3' \\
\hline MxA & $5^{\prime}$-GTGAGATCAGCTCCCGAGATG-3' & 5'-ATTGCCCACAGCCACTCTG-3' \\
\hline IL-6 & $5^{\prime}$-GTGTGAAAGCAGCAAAGAGGC-3' & $5^{\prime}$-TGCAGGAACTGGATCAGGACT-3' \\
\hline IL-8 & 5'-TCTCTTGGCAGCCTTCCTGA-3' & 5'-CGCAGTGTGGTCCACTCTCA-3' \\
\hline Human $\beta$-actin & $5^{\prime}$-TCACCCACACTGTGCCCATCTACGA-3' & $5^{\prime}$-CAGCGGAACCGCTCATTGCCAATGG-3' \\
\hline
\end{tabular}

$10 \mathrm{~min}, 40$ cycles of $95^{\circ} \mathrm{C}$ for $15 \mathrm{~s}, 62^{\circ} \mathrm{C}$ for $30 \mathrm{~s}$ and $72^{\circ} \mathrm{C}$ for $15 \mathrm{~s}$. After amplification was complete, a final melting curve is performed with $2 \mathrm{~min}$ of denaturation at $95^{\circ} \mathrm{C}$, then cooling to $60^{\circ} \mathrm{C}$ and heating slowly until $95^{\circ} \mathrm{C}(15 \mathrm{~min})$ according to the dissociation protocol of the ABI7700 instrument. Real-time fluorescence measurement was read and a threshold cycle $\left(C_{\mathrm{T}}\right)$ value for each sample was calculated by determining the point at which the fluorescence exceeds a threshold limit, that is 10 times above the s.d. of the baseline. The $C_{\mathrm{T}}$ value from the samples was plotted on the standard curve, and the copy number was calculated automatically with Sequence Detection Version 1.6 (PE Applied Biosystems). Each sample was tested in duplicate and the mean of the two values were chosen as copy number of the sample. Samples were defined as negative if the $C_{\mathrm{T}}$ values exceeded 50 cycles. Primers and Probes for the target genes were chosen with the assistance of computer program Primer Express (Perkin-Elmer Applied Biosciences, Foster City, CA). The mRNA of the $\beta$ actin was chosen as internal control in each sample to control sample to sample variations in RNA concentration. To validate the transcripts obtained by QRT-PCR, cDNA from three random liver samples were used for serial dilution $(1: 2,1: 4,1: 16$ and $1: 32$ ) to obtain a relative standard curve, which revealed a perfect correlation throughout the dilutions $\left(R^{2}=0.99\right)$. The validation experiments were carried out in triplicate and amplification efficiencies were validated. ${ }^{21}$

\section{Immunohistochemistry}

Immunoreactive TLR7 and MxA staining were performed on paraffin-embedded, formalin fixed, archival liver tissues obtained from the Department of Pathology. Two micrometer sections were deparaffinized, treated with $3 \%$ hydrogen peroxide to inactivate the endogenous peroxidase activity and microwaved for $10 \mathrm{~min}$ in $10 \mathrm{mM}$ citrate buffer to retrieve antigen. Then the sections incubated in $2 \%$ normal horse serum (Vector, Burlingame, CA, USA) for $10 \mathrm{~min}$ to block the background. The sections were incubated with rabbit anti-TLR7 antibody (Zymed Laboratories, South San Francisco, and Cat. no. 36-6500, 1:100 dilution) at room temperature $1 \mathrm{~h}$ and mouse monoclonal anti-MxA antibody (M143), a gift from Dr Otto Haller (University of Freiburg, Germany, 1:100 dilution) at room temperature for $1 \mathrm{~h}$ and overnight, respectively. ${ }^{22}$ The sections were then washed with TBS and detected by second antibody with SuperPicTure ${ }^{\mathrm{TM}}$ Polymer detection kit (Zymed Laboratories, South San Francisco, and Cat. no. 87-8963) and DAB chromogen (DAKO, USA, Cat. no. K3467) according to manufacturer's instructions. As TLR7 and MxA were expressed in hepatitis $C$ and $B$ virus infected liver, respectively, ${ }^{23,24}$ a liver sample from one hepatitis $\mathrm{C}$ and B infected patient served as positive control. Negative controls were the sample from a patient in the early stage of BA without treatment with the primary antibody. The CO was the liver tissue obtained from patients without liver fibrosis and cholestasis and disease control was from patients with CC and neonatal hepatitis (NH), respectively. The immunoreactivity was scored with semiquantitative scoring method: score 1-3: the areas of positive cells in hepatic lobules, hepatic sinusoid, portal areas and fibrous plate were less than $10 \%$, $10-50 \%$, more than $50 \%$ of total liver tissues, respectively.

\section{Statistical Analysis}

All values in the figures and tables are expressed as mean \pm s.e. Student's $t$-test (unpaired, two-tailed) was used for comparison between experimental groups. Differences in the distribution of staining score between groups were assessed with MannWhitney $U$ test. A $P$-value $<0.05$ was considered as statistically significant.

\section{Results}

\section{TLR, MxA, IL-6 and IL-8 mRNA Expression}

Among the five TLRs studied, we found that only TLR7 expression significantly elevated in the early 


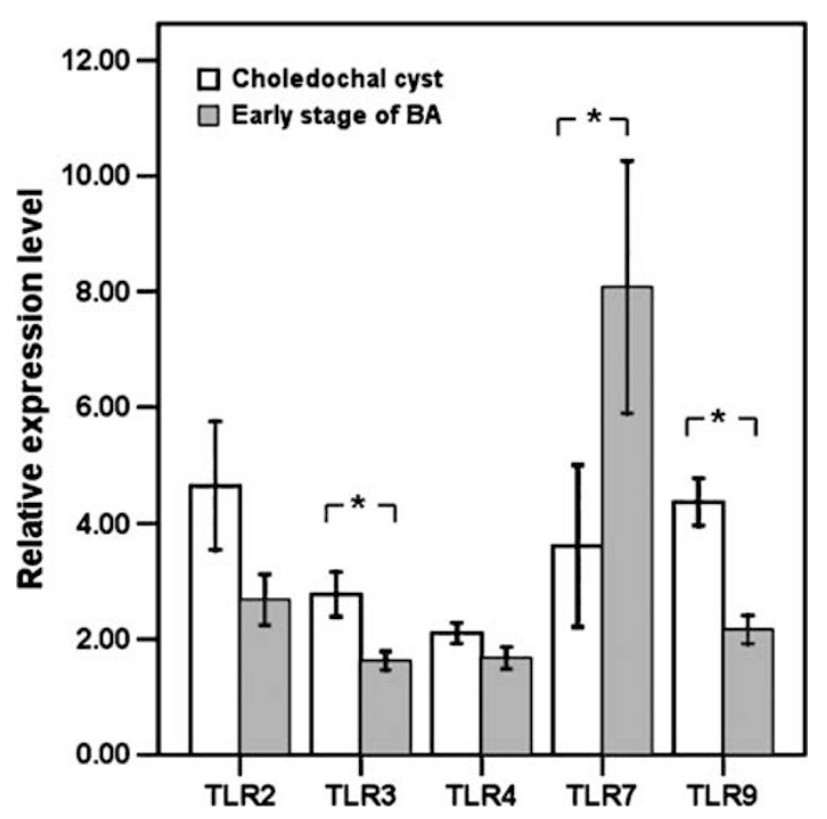

Figure 1 Comparison of TLR2, 3, 4, 7 and 9 mRNA expressions by QRT-PCR between early stage of BA and CC. Data are expressed as mean \pm s.e. of 10 samples in each group. *Sign indicates significant difference between groups $(P<0.05)$.

stage of BA than in CC $(P=0.02)$ (Figure 1). There was no significant difference in TLR2 and TLR4 expressions between the early stage of BA and CC. On the contrary, we found significant decrease of TLR3 and TLR9 mRNA expression in the early stage of BA than in CC ( $P=0.01$ and 0.001 , respectively) (Figure 1).

We further studied TLR7 mRNA expression and found the level was significantly higher in the early stage than in the late stage of BA $(P=0.03)$ (Figure 2). Although TLR7 mRNA expression was higher in the early stage of BA than in CO (relative ratio $3.62 \pm 0.98, P=0.09$ ), the difference was not significant, probably due to small sample size of normal control. As TLR7 is a receptor for RNA virus that can induces type 1 interferon specific gene and protein expression, we studied MxA mRNA expressions. The results demonstrated higher MxA expressions in the early stage of BA and in CC than in the late stage of BA $(P=0.02)$. However, there was no significant difference between early stage of BA and CC and CO, too $(P=0.53$ and 0.13 , respectively) (Figure 2).

In order to clarify TLR-induced proinflammatory gene expression, we studied proinflammatory IL-6 and IL-8 expression. There was significantly higher IL-8 mRNA expression in both the early and late stages of BA than in CC $(P=0.03$ and 0.04, respectively) (Figure 3). There was also significantly higher expression of IL-6 mRNA expression in the late stage of BA than in CC. There was no significant difference in IL-6 and IL-8 mRNA expression between the early and late stages of BA.

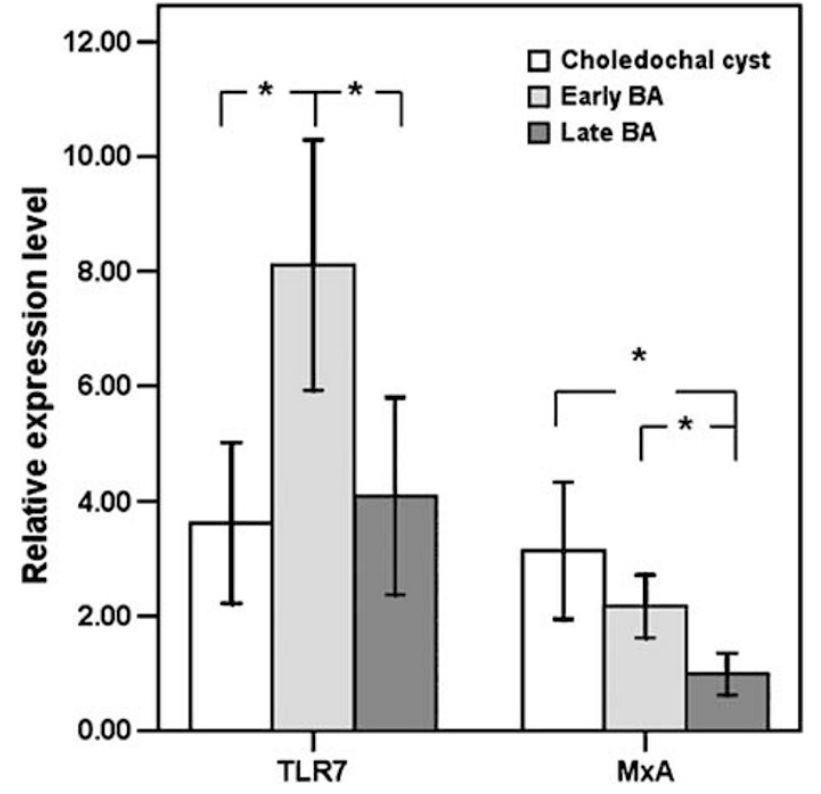

Figure 2 TLR7 and MxA mRNA expression in the early stage and late stage of BA, CC are shown. Data are expressed as mean \pm s.e. of 10 samples in each group. *Indicates significant difference between groups $(P<0.05)$.

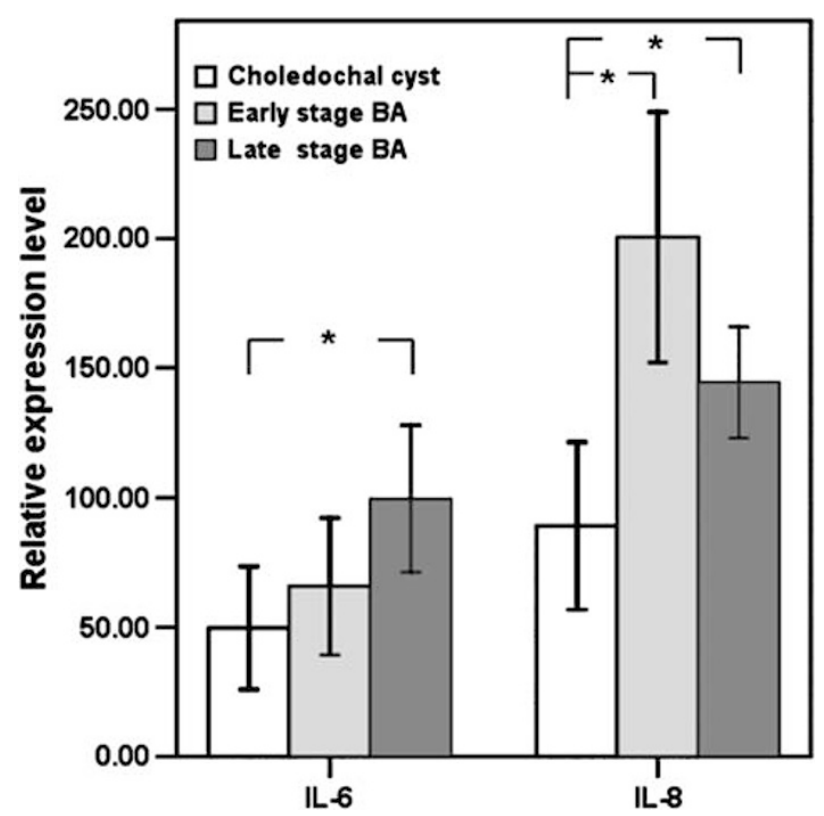

Figure 3 Comparing the IL-6 and IL-8 mRNA expressions in the early and late stage of BA with CC. Data are expressed as mean \pm s.e. of 10 samples in each group. ${ }^{*}$ Indicates significant difference between groups $(P<0.05)$.

\section{Immunoreactive TLR7 Staining in BA}

To further characterize TLR7 protein expression in the liver, immunohistochemical staining was carried out. Strong TLR7 immunoreactivity was present in the bile ductular epithelial cells, some nonparenchymal cells morphologically identical to Kupffer 


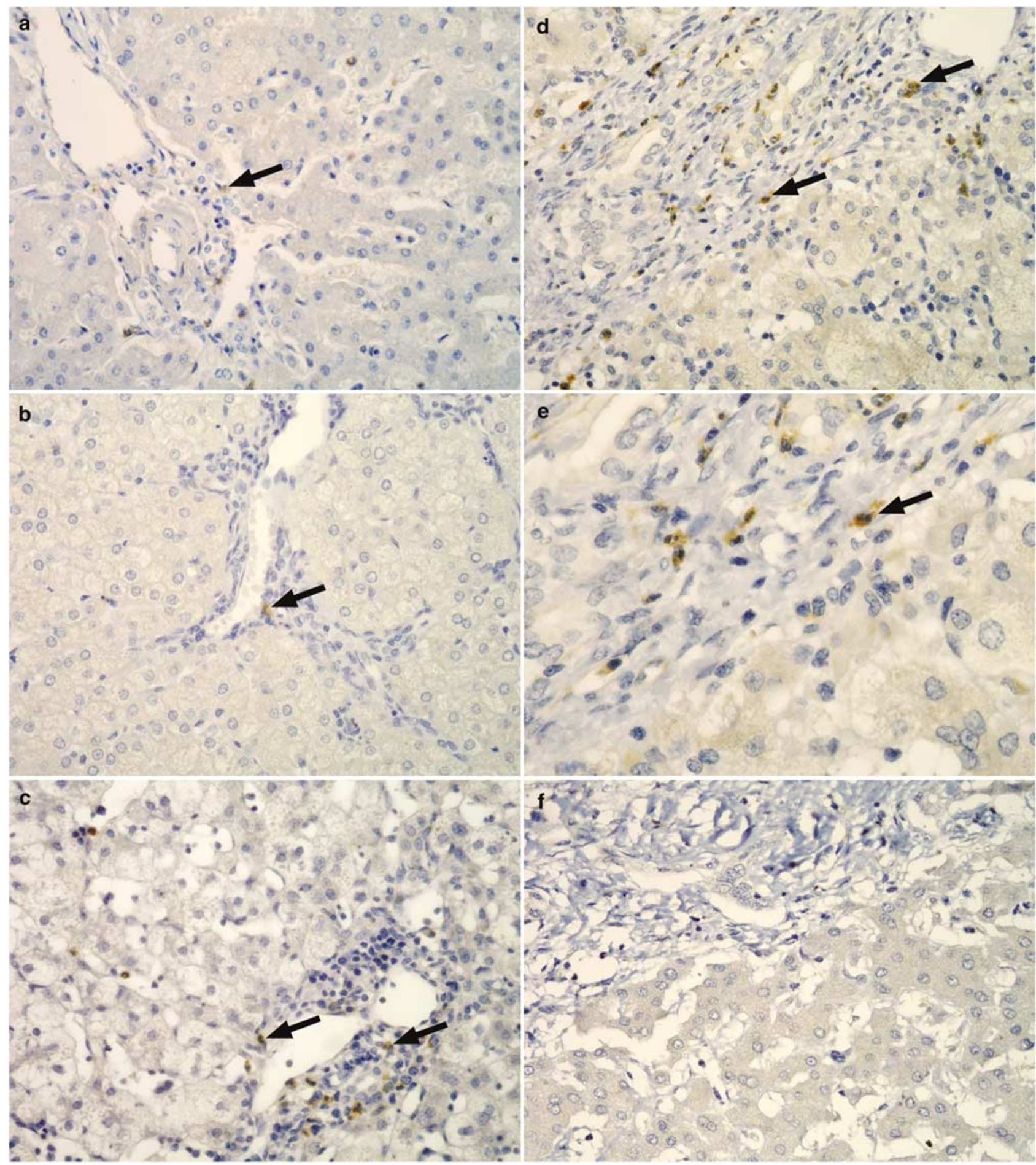

Figure 4 Immunohistochemical studies of TLR7 protein expression in the liver tissue. The representative normal control was the nonneoplastic part of the liver tissue obtained from a patient with hepatoblastoma receiving surgical resection. The representative disease control was obtained from a patient with CC and with NH. The liver tissues of BA were obtained from the same patient when she received Kasai operation at one month old and then liver transplantation at 23 months old, respectively. (a) In control liver, TLR 7 immunoreactivity is mainly found in the neutrophils (arrows) and faintly present in the hepatocytes. (b) In CC, TLR7 immunoreactivity is also found in few neutrophils (arrows) and weakly present in the hepatocytes. (c) In NH, TLR 7 immunoreactivity is mainly found in the neutrophils (arrows) and no immunoreactivity in the hepatocytes. (d) In early stage of BA, increased TLR 7 immunoreactivity is noted in the cytoplasm of the hepatocytes and the bile ductular epithelial cells as well as in the neutrophils (arrows). (e) This figure is a high power image of (d) and it shows increased TLR 7 immunoreactivity in the cytoplasm of the hepatocytes as well as in the darkly staining neutrophils (arrows). (f) In the late stage of BA, only weak TLR7 immunoreactivity is shown in the hepatocytes and the neutrophils but not in the bile ductular epithelial cells. (Original magnification $\times 400$, except $(\mathbf{e}) \times 800$ ). 
Table 3 Intensity of TLR7 and MxA immunostaining

\begin{tabular}{|c|c|c|c|c|c|}
\hline Immunostaining & $\begin{array}{l}\text { Early stage of } B A \\
\qquad \mathrm{n}=6\end{array}$ & $\begin{array}{l}\text { Late stage of } B A \\
\mathrm{n}=4\end{array}$ & $\begin{array}{l}\text { Choledochal cyst } \\
\qquad \mathrm{n}=7\end{array}$ & $\begin{array}{l}\text { Neonatal hepatitis } \\
\mathrm{n}=4\end{array}$ & $\begin{array}{c}\text { Contro } \\
\mathrm{n}=4\end{array}$ \\
\hline \multicolumn{6}{|l|}{ TLR7* } \\
\hline 1 & 0 & 1 & 2 & 3 & 2 \\
\hline 2 & 0 & 3 & 3 & 1 & 2 \\
\hline 3 & 6 & 0 & 2 & 0 & 0 \\
\hline \multicolumn{6}{|l|}{$M x A^{* *}$} \\
\hline 1 & 0 & 2 & 0 & 1 & 2 \\
\hline 2 & 3 & 2 & 5 & 3 & 2 \\
\hline 3 & 3 & 0 & 2 & 0 & 0 \\
\hline
\end{tabular}

$n=$ numbers of the patients, ${ }^{*} P<0.05$ compared early stage of BA to late stage, choledochal cyst, neonatal hepatitis and control, ${ }^{* *} P<0.05$ compared early to late stage of BA and control.

cells and neutrophils, and weaker expression in the cytoplasm of hepatocytes in the early stage of BA, which was higher than in the late stage of $\mathrm{BA}, \mathrm{CO}$, $\mathrm{NH}$ and CC (Figure 4). In the late stage of BA, TLR7 expression decreased significantly in the hepatocytes and the bile ductular epithelial cells. The results demonstrated significant increase in TLR7 expression in the early stage of $\mathrm{BA}$ than in the late stage of BA and CC (Table 3). In CC, TLR7 immunostaining, although weaker than BA, became more conspicuous in hepatocytes, not in the bile ductular epithelial cells and Kupffer cells. The trend of TLR7 protein expression was consistent with TLR7 mRNA expression.

\section{Immunoreactive MxA Expression in BA}

Comparing to the late stage of $\mathrm{BA}, \mathrm{NH}$ and normal control, there was stronger MxA immunostaining in the bile ductular epithelial cells, Kupffer cells and the cytoplasm of hepatocytes in the early stage of BA (Figure 5). The trend of MxA protein expression was also consistent with the results of MxA mRNA expression (Table 3).

The relative expression levels of mRNA and immunoreactive staining scores were listed on Table 4.

\section{Discussion}

Our results demonstrate for the first time the expression of TLRs in BA and found significantly higher TLR7 and protein expression in the early stage of BA than in the late stage of BA, and CC. Meanwhile, there was significantly higher type I interferon specific MxA mRNA and protein expression in the early stage of BA than in the late stage. TLRs are the most recognized pattern recognition receptors, which recognize infectious pathogens and activate type 1 interferon and induce inflammatory response gene expression. The latter includes IL-8 in this study.
TLR7 has been identified as the receptor for single-stranded RNA virus and induces type 1 interferon inflammatory cascades for antiviral activity mediated by MxA. ${ }^{15,16} \mathrm{MxA}$ is a $76 \mathrm{kDa}$ GTPase protein which possesses many of the biophysical properties of conventional dynamin proteins known to be involved in intracellular membrane trafficking. ${ }^{16}$ In vivo and in vitro studies show that MxA is able to inhibit a broad spectrum of negative and positive strand RNA viruses. ${ }^{25-28}$ High levels of MxA protein were found in the peripheral blood cells of the patients with acute viral infections such as rotavirus, adenovirus, respiratory syncytial virus, cytomegalovirus and hepatitis $\mathrm{C}$ virus but not elevated in bacterial infections. ${ }^{27,28}$ Therefore, its quantitation can be considered as a specific marker of acute viral infections. ${ }^{27}$ As infectious pathogens, particular viruses, have been suggested as the causative agents in BA, we speculate from this study that elevated TLR7 and MxA expression in the early stage of BA may represent a response to viral infection, but evidence to prove it is still lacking.

In addition to their roles in mediating infection, TLRs are also known to involve in complex tissue damage and remodeling inflammatory pathways. ${ }^{29}$ There is evidence that endogenous ligands such as damaged cells or stressed cells in the abscess can initiate an immune response through TLRs and trigger an immune/inflammatory response. ${ }^{30,31} \mathrm{Up}$ regulation of TLR7 expression has been reported in noninfectious condition, such as in the skeletal muscle in early stage of Duchenne muscular dystrophy. ${ }^{31}$ From these perspective, upregulation of TLR7 in the early stage BA may also imply a simple immune response to active inflammation and liver tissue damage characteristic of that stage of BA.

TLR7 can modulate human CD4 $\mathrm{T}$ cells to upregulate proliferation and IL-8 production. ${ }^{32}$ The function of IL-8 is not only a potent recruiter of neutrophils and $\mathrm{T}$ cells but also a potent stimulator of the degranulation and of the respiratory burst in neutrophils. ${ }^{33}$ More recently, elevated serum IL-8 is found in BA and higher serum IL-8 significantly 


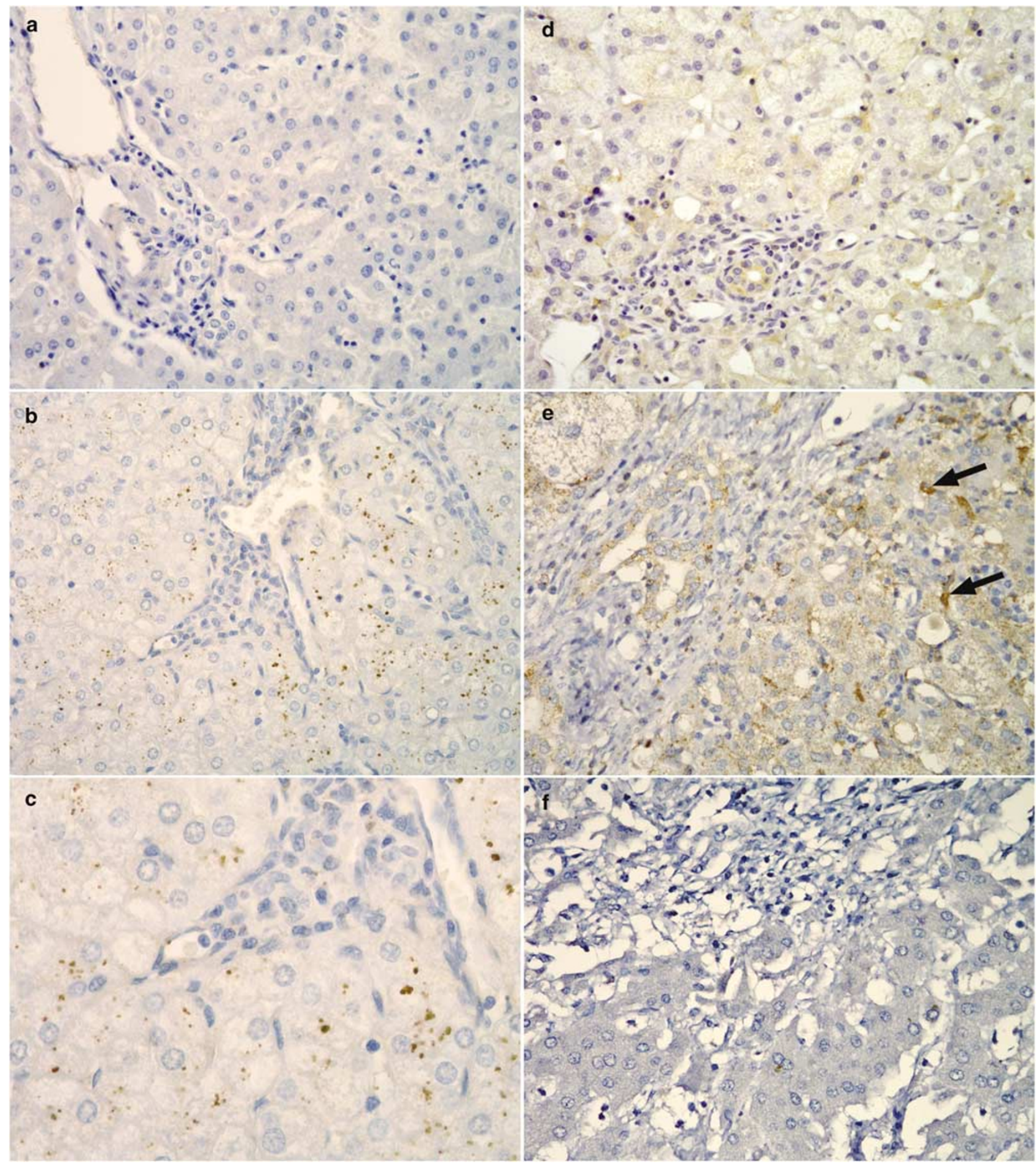

Figure 5 Immunohistochemical studies of MxA protein expression in the liver tissue. The liver tissues were from the same patients as described in (a) In control liver, no MxA immunoreactivity is present. (b) In CC, MxA immunoreactivity is demonstrated as scattered dotlike signals mainly in the hepatocytes. (c) This figure is a high-power image of (b), which shows MxA immunoreactivity staining mainly in cytoplasm of hepatocytes. Some bile pigments may be present in the image. (d) In NH, MxA immunoreactivity is mainly found in the cytoplasm of the hepatocytes, bile ductular epithelial cells. (e) In early stage of BA, distinct MxA immunoreactivity is noted in the cytoplasm of the hepatocytes, bile ductular epithelial cells and Kupffer cells (arrows). The Kupffer cells demonstrate the most intense immunoreactivity. (f) In the late stage of BA, only focal, dot-like signals of MxA immunoreactivity are noted in the hepatocytes. (Original magnification $\times 400$, except $(\mathbf{c}) \times 800)$.

correlated with the degree of fibrosis scored with the histologic activity index, patient with jaundice, and portal hypertension. ${ }^{34,35}$
One interesting finding is significantly lower expression of TLR3 and TLR9 in the early stage of BA than in CC.TLR3 and TLR9 are receptors for 
Table 4 Fold difference in real-time QRT-PCR and relative protein expression in immunohistochemistry

\begin{tabular}{|c|c|c|c|c|}
\hline \multirow[t]{2}{*}{ Gene } & \multicolumn{2}{|c|}{ Fold difference in QRT-PCR } & \multicolumn{2}{|c|}{ Relative protein expression } \\
\hline & Early stage $B A / C C$ & Early stage $B A /$ late stage $B A$ & Early stage BA/CC & Early stage $B A /$ late stage $B A$ \\
\hline TLR2 & $0.58 \pm 0.30$ & NA & NA & NA \\
\hline TLR3 & $0.59 \pm 0.18^{*}$ & NA & NA & NA \\
\hline TLR4 & $0.80+0.29$ & NA & NA & NA \\
\hline TLR7 & $2.24 \pm 1.90^{*}$ & $1.98 \pm 1.69 *$ & Increased* & Increased* \\
\hline TLR9 & $0.50 \pm 0.18^{*}$ & NA & NA & NA \\
\hline $\mathrm{MxA}$ & $0.69 \pm 0.55$ & $2.20 \pm 1.76^{*}$ & Increased & Increased* \\
\hline IL-6 & $1.32 \pm 1.68$ & $0.66 \pm 0.84$ & NA & NA \\
\hline IL-8 & $2.25 \pm 1.71^{*}$ & $1.39 \pm 1.06$ & NA & NA \\
\hline
\end{tabular}

The QRT-PCR ratio is the relative level of transcripts measured by real-time QRT-PCR in one group over that in the other.

$\mathrm{BA}=$ biliary atresia, $\mathrm{CC}=$ choledochal cyst, $\mathrm{NA}=$ not available. ${ }^{*} P<0.05$.

recognition of double-stranded RNA virus and CpG dinucleotides, respectively. Th2 cytokines including IL-4 and IL-13 are known to decrease TLR3 mRNA and protein expression in human intestinal epithelial cells, which is suspected to be a protective mechanism that prevents host from excessive TLR signaling. ${ }^{36}$ Improved graft acceptance in young infants comparing to the elder children with BA receiving liver transplantation also implies a protective role of Th2 cytokines. ${ }^{37}$ Whether the observed decreased hepatic TLR3 expression in the early stage of BA is a protective reaction from ongoing inflammatory process is unknown at present, because of lack of sufficient data that address the expression of Th2 cytokines in BA. In the normal infants, the T-helper phenotype in circulating mononuclear cells are toward a Th2 polarity before antigen exposure. ${ }^{38}$ Bezerra et $a l^{39}$ demonstrated that an upregulation of proinflammatory cytokine osteopontin and interferon- $\gamma$ that regulate Th1 immune response and downregulation of immunoglobulin domain consistent with suppression of Th2 response at the time of diagnosis of BA and during the progression to biliary cirrhosis.

Diminished TLR9 expression was found in one report of lymphatic filariasis and was suspected to be a likely consequence of chronic antigen stimulation that could explain dysfunctional immune response in filariasis. ${ }^{40}$ It is also uncertain if in the early stage of BA, the decreased TLR9 expression is the consequence of chronic stimulation by some yet unidentified antigens.

In conclusion, the results of this study indicate that TLR signaling might play an important role in the pathogenesis of nonsyndromic BA, which is associated with upregulation of type I interferon specific protein MxA and inflammatory cytokine IL-8. However, the exact mechanism that underlies up-regulation of TLR7 and down-regulation of TLR3 and TLR9 in the early stage of BA when the disease is first diagnosed is waiting to be clarified.

\section{Acknowledgements}

We thank Dr Otto Haller for his kind gift of the antiMxA antibody used in this study and the liver transplant team of this hospital, led by professor Chao-Long Chen, for their assistance in this study. This study was supported by Chang Gung Memorial Hospital with the Grant no. CMRPG84014 and the National Science Council with the Grant no. NSC952314-B-182-025-MY2.

\section{Duality of interest}

None declared.

\section{References}

1 Chen CL, Chen YS, de Villa VH, et al. Minimal blood loss living donor hepatectomy. Transplantation 2000;69:2580-2586.

2 Jain A, Reyes J, Kashyap R, et al. Long-term survival after liver transplantation in 4,000 consecutive patients at a single center. Ann Surg 2000;232: 490-500.

3 Fischler B, Ehrnst A, Forsgren M, et al. The viral association of neonatal cholestasis in Sweden: a possible link between cytomegalovirus infection and extrahepatic biliary atresia. J Pediatr Gastroenterol Nutr 1998;27:57-64.

4 Drut R, Drut RM, Gomez MA, et al. Presence of human papillomavirus in extrahepatic biliary atresia. J Pediatr Gastroenterol Nutr 1998;27:530-535.

5 Bobo L, Ojeh C, Chiu D, et al. Lack of evidence for rotavirus by polymerase chain reaction/enzyme immunoassay of hepatobiliary samples from children with biliary atresia. Pediatr Res 1997;41:229-234.

6 Mason AL, Xu L, Guo L, et al. Detection of retroviral antibodies in primary biliary cirrhosis and other idiopathic biliary disorders. Lancet 1998;351: 1620-1624.

7 Petersen C, Biermanns D, Kuske M, et al. New aspects in a murine model for extrahepatic biliary atresia. J Pediatr Surg 1997;32:1190-1195. 
8 Riepenhoff-Talty M, Schaekel K, Clark HF, et al. Group A rotaviruses produce extrahepatic biliary obstruction in orally inoculated newborn mice. Pediatr Res 1993;33:394-399.

9 Shivakumar P, Campbell KM, Sabla GE, et al. Obstruction of extrahepatic bile ducts by lymphocytes is regulated by IFN-gamma in experimental biliary atresia. J Clin Invest 2004;114:322-329.

10 Perry AK, Chen G, Zheng D, et al. The host type I interferon response to viral and bacterial infections. Cell Res 2005;15:407-422.

11 Akira S, Hemmi H. Recognition of pathogen-associated molecular patterns by TLR family. Immunol Lett 2003;85:85-95.

12 Decker T, Stockinger S, Karaghiosoff K, et al. IFNs and STATs in innate immunity to microorganisms. J Clin Invest 2002;109:1271-1277.

13 Moynagh PN. TLR signaling and activation of IRFs: revisiting old friends from the NF- $\kappa \mathrm{B}$ pathway. Trends Immunol 2005;26:469-476.

14 Petersen C, Bruna E, Kuske M, et al. Treatment of extrahepatic biliary atresia with interferon-alpha in a murine infectious model. Pediatr Res 1997;42: 623-628.

15 Haller O, Frese M, Kochs G. Mx proteins: mediators of innate resistance to RNA viruses. Rev Sci Tech 1998; 17:222-230.

16 Haller O, Kochs G. Interferon-induced mx proteins: dynamin-like GTPases with antiviral activity. Traffic 2002;3:710-717.

17 Soderblom T, Oxhamre C, Torstensson E, et al. Bacterial protein toxins and inflammation. Scand J Infect Dis 2003;35:628-631.

18 Benhidjeb T, Ridwelski K, Wolff H, et al. Anomaly of the pancreatico-biliary junction and etiology of choledochal cysts. Zentralbl Chir 1991;116:1195-1203.

19 Schroeder D, Smith L, Prain HC. Antenatal diagnosis of choledochal cyst at 15 weeks' gestation: etiology implications and management. J Pediatr Surg 1989;24: 936-938.

20 Gibson UE, Heid CA, Williams PM. A novel method for real time quantitative RT-PCR. Genome Res 1996;6: 995-1001.

$21 \mathrm{Li}$ AC, Brown KK, Silvestre MJ, et al. Peroxisome proliferator-activated receptor gamma ligands inhibit development of atherosclerosis in LDL receptordeficient mice. J Clin Invest 2000;106:523-531.

22 Flohr F, Schneider-Schaulies S, Haller O, et al. The central interactive region of human MxA GTPase is involved in GTPase activation and interaction with viral target structures. FEBS Lett 1999;463:24-28.

23 Lee J, Wu CC, Lee KJ, et al. Activation of anti-hepatitis $\mathrm{C}$ virus responses via toll-like receptor 7. Proc Natl Acad Sci USA 2006;103:1828-1833.

24 MacQuillan GC, de Boer WB, Platten MA, et al. Intrahepatic $\mathrm{MxA}$ and $\mathrm{PKR}$ protein expression in chronic hepatitis C virus infection. J Med Virol 2002; 68:197-205.
25 Frese M, Kochs G, Feldmann H, et al. Haller. Inhibition of bunyaviruses, phleboviruses, and hantaviruses by human MxA protein. J Virol 1996;70:915-923.

26 Pavlovic J, Zurcher T, Haller O, et al. Resistance to influenza virus and vesicular stomatitis virus conferred by expression of human MxA protein. J Virol 1990;64:3370-3375.

27 Chieux V, Hober D, Harvey J, et al. The MxA protein levels in whole blood lysates of patients with various viral infections. J Virol Methods 1998;70: 183-191.

28 MacQuillan GC, de Boer WB, Platten MA, et al. Intrahepatic $\mathrm{MxA}$ and $\mathrm{PKR}$ protein expression in chronic hepatitis C virus infection. J Med Virol 2002; 68:197-205.

29 Barton GM, Medzhitov R. Toll-like receptor signaling pathways. Science 2003;300:1524-1525.

30 Matzinger P. The danger model: a renewed sense of self. Science 2002;296:301-305.

31 Chen YW, Nagaraju K, Bakay M, et al. Early onset of inflammation and later involvement of TGF beta in Duchenne muscular dystrophy. Neurology 2005; 65:826-834.

32 Caron G, Duluc D, Fremaux I, et al. Direct stimulation of human T cells via TLR5 and TLR7/8: flagellin and R-848 up-regulate proliferation and IFN-gamma production by memory CD4+ T cells. J Immunol 2005;175: 1551-1557.

33 Baggiolini M, Dewald D, Moser B. Interleukin-8 and related chemotactic cytokines: CXC and CC chemokines. Adv Immunol 1994;55:97-179.

34 Nobili V, Marcellini M, Giovannelli L, et al. Association of serum interleukin-8 levels with the degree of fibrosis in infants with chronic liver disease. J Pediatr Gastroenterol Nutr 2004;39:540-544.

35 Honsawek S, Chongsrisawat V, Vejchapipat $\mathrm{P}$, et al. Serum interleukin-8 in children with biliary atresia: relationship with disease stage and biochemical parameters. Pediatr Surg Int 2005;21:73-77.

36 Mueller T, Terada T, Rosenberg IM, et al. Th2 cytokines down-regulate TLR expression and function in human intestinal epithelial cells. J Immunol 2006;176: 5805-5814.

37 Ganschow R, Broering DC, Nolkemper D, et al. Th2 cytokine profile in infants predisposes to improved graft acceptance after liver transplantation. Transplantation 2001;72:929-934.

38 Prescott SL, Macaubes C, Yabuhara A, et al. Developing pattern of $\mathrm{T}$ cell memory to environment allergens in the first two years of life. Int Arch Allergy Immunol 1997;113:75-79.

39 Bezerra JA, Tiao G, Ryckman FC, et al. Genetic induction of proinflammatory immunity in children with biliary atresia. Lancet 2002;360:1653-1659.

40 Babu S, Blauvelt CP, Kumaraswami V, et al. Diminished expression and function of TLR in lymphatic filariasis: a novel mechanism of immune dysregulation. J Immunol 2005;175:1170-1176. 